\title{
Trade-Off Phillips Curve, Inflation and Economic Implication: The Kenyan Case
}

\author{
Hongo Omenda Duncan ${ }^{1}$, Fanglin $\mathrm{Li}^{1} \&$ Max W. Ssali ${ }^{2}$ \\ ${ }^{1}$ School of Finance and Economics, Jiangsu University, Zhenjiang, Jiangsu, P. R. China \\ ${ }^{2}$ School of Management, Jiangsu University, Zhenjiang, Jiangsu, P. R. China \\ Correspondence: Hongo Omenda Duncan \& Fanglin Li, School of Finance and Economics, Jiangsu University, \\ Zhenjiang, Jiangsu, 212013, P. R. China. Tel: 86-178-2607-3502. E-mail: dancanome@ yahoo.com/ \\ lifanglin@ujs.edu.cn
}

Received: January 13, 2019

Accepted: February 14, 2019

Online Published: March 15, 2019

doi:10.5539/ijef.v11n4p60

URL: https://doi.org/10.5539/ijef.v11n4p60

The Research is Funded by National Natural Science Foundation China of grant number [71503105].

\begin{abstract}
This paper investigated the trade-off and inflation drivers based on the Phillips curve framework to determine the relationship and their impact between inflation, unemployment and output for Kenyan case from 2006:M1 to 2016:M12 by contrasting the 2SLS on 2 different measures of marginal cost with 3 differently instrumented shocks. Results confirmed; (1) significant trade-off that reduced inflation by $2.09 \%$ and $0.08 \%$ when unemployment and output respectively increase by $1 \%$, while, $1 \%$ increase in output demeaned unemployment by $0.02 \%$, (2) the forward-looking inflation and unemployment significantly drive observed inflation, and (3) unlike monetary supply, oil shocks best accounts for the observed dynamics. Although laudable policies been implemented by fiscal and macro-economic planners, they have not achieved the odds to sufficiently contain the import shocks, making both unemployment and the rational expectations to significantly drive the observed inflation. However, revisiting of the incumbent fiscal policies and their tight implementation would facilitate long term price stabilities to reduce the inflationary dynamics. To the significant import shocks, the state should foster feasible macro-economic diversifications, investments policies, modern technologies in real economic activity production, and renewable energy sourcing that would facilitate robust economic growth that would curb large revenue outflows due to commodity imports and cushioning the devaluation of the Kenyan shilling.
\end{abstract}

Keywords: Phillips curve, inflation, trade-off, shocks, unemployment, inflationary targeting

\section{Introduction}

Equally, to macro-economic policy practitioners in developed and emerged economies, in Kenya, they would consent that, inflation has many detrimental puzzling effects on economic development more so in pursuant of price stability, low unemployment and stabilizing interest rates. This is because high economic growth that is known to correlate with low inflation rates and positive externalities has yet not achieved. Similarly, despite the high economic growth since past decades, Kenya has, however, experienced relatively high inflation with negative macroeconomic impacts (Casares, Moreno, \& Vázquez, 2014; Durevall \& Sjö, 2012; Misati \& Munene, 2015; Nyongesa, Lubega Amlega, \& Odhiambo, 2017; Roseline Nyakerario Misati, 2012).

High inflation rates have known to depress interest rates and investments in favor of consumer activities which at times, have demeaned output growth and employment. In this case, the central bank that would otherwise instigate some inflationary targeting measures, might bring below their natural rates; unemployment and output thus destabilizing the financial markets. This distorts inflation expectations and sustainable discount rates. Consequently, commercial banks would have their lending advantages eroded as they accordingly raise the lending rates to the already conservative consumers and populace at large. This demeans business activities in the economy. Equally, foreign trade activities almost diminish because of high price tags imposed on exports demeaning their favorable competition on the global market. Subsequently, trade imbalance that in turn materialize negatively affects the economy. In a counter attempt, industries and employers are coerced to dedicate a considerable level of resources and forego creation of employment opportunities to investigate and anchor the sources and effects of these shocks (Durevall \& Sjö, 2012; Gil-Alana \& Mudida, 2017; Gokal \& 
Hanif, 2004; Were, Nyamongo, Kamau, Sichei, \& Wambua, 2014). On the other hand, workers who have already revised their wage rates upwards to suffice the eroding inflation effects depresses the expenditure phobic employers who freeze employment. Ultimately, unemployment trades-off with inflation as economic growth largely relates negatively with the high inflation (Gokal \& Hanif, 2004; Nyongesa et al., 2017). In contrast, low inflation has known to increase real interest rates, foreign and domestic investments, capital accumulation and circulation, and general increase in economic activities that enhances economic growth.

In Kenya, inflation that is driven by both supply side, demand side and policy shocks; global oil shocks and food prices, exchange rates, fiscal and monetary policies, agricultural among others, has negatively influenced economic development (Durevall \& Sjö, 2012; Misati \& Munene, 2015). In addition, short-term political instabilities have also shocked the economy like in 1990 (Gil-Alana \& Mudida, 2017) and the 20007/8 political instabilities. However, global oil crisis and natural calamities in the agricultural sector have demeaned the economy to the long run. All along, the shocks have largely devastated core macro-economic sectors with considerable economic downturns. The period 2007/8 was coincidental where political instabilities, global oil crisis, domestic and policy shocks induced stagflationary gap. Consumer prices rose sharply from $4.3 \%$ in 2007 to $15.1 \%$ in 2008 partly due to the devastated agricultural sector that promoted food insecurity and a significant recession in output and employment. GDP dropped significantly from over 6\% in 2007 to as below $2 \%$ in 2008 (Durevall \& Sjö, 2012). Uncertainly, unemployment sharply scaled from $10.9 \%$ (2008) to $12.2 \%$ (2009). From 2010 , the unemployment trended downward gradually close to $11.5 \%$ in 2017 . Our monthly data similarly depicts the downward trend in unemployment from around 2010 as in figure 2 and 4. However, still in 2007/8 economic crisis, inflation increased by over 29\% (Durevall \& Sjö, 2012), and the instigated monetary policy implemented was to impartially reduce the discount rate. The effectively increased economic and business activities, saw economic recovery that effectively subsided inflation to below the Central Banks' $5 \%$ target in 2011M2 (see fig 1). Again, inflation trended upward from the proceeding month further devaluating the Kenyan shilling. The Central Bank of Kenya (CBK) responded by hiking the interest rate from $2 \%$ to over $17 \%$ that saw appreciation of the shilling by Ksh.20 to Ksh.100 per U.S \$ in 2011M;10 with an upheld tight monetary policy rate (Durevall \& Sjö, 2012), although GDP was still low at less than $4.4 \%$.

Moreover, economic growth that had been slackened greatly by the 2008 global recession and local shocks presumed recovery in 2013 at 4.4\%, through $5.5 \% 2015$ to reach 5.79\% in 2016, which manifested the country as a rapidly growing, and in the same year ranked $9^{\text {th }}$ best in Sub-Saharan Africa (World bank, 2018; Kenya Economic Report, 2017). The recovery attributed to growth experienced in major macroeconomic sectors (Note 1), that boosted the business environment. In addition, adoption of devolved system of governance courtesy of the 2010 constitution that steered new political and supremacy systems, energized the promotion of equitable resource distribution, service delivery and culpability of public resources countrywide. This had a stake in reshaping the economy (ERA, 2016; KER, 2017).

So far, the country has been yearning for low inflation and economic development through inflation targeting and sustainable economic growth policies. The central bank and other fiscal policy strategists are part of the syndicate largely been embracing such policies (Gil-Alana \& Mudida, 2017; Were et al., 2014) to anchor low inflation dynamics as macro-economic planners advocates for fostering economic diversification, development of resilient regional integration as avenues to boost export. The country is one of the few in sub-Saharan Africa that have significantly embraced macro-economic model tools and policies since the new millennium to plan fiscal activities (Were et al., 2014). To name a few, the KIPPRA-Treasury Macroeconomic model (Note 2) developed in 2000 in a Kenyan policy research institute affiliated with the treasury was key to fiscal policy planning mainly through prediction of macro-economic variables (Huizinga, Geda, Ndun'gu, \& Karingi, 2001; Were et al., 2014). In 2011 a more superior than the KIPPRA tool was developed; the central bank of Kenya (CBK) model (Note 3) whose objectives since then have been to model fiscal policies and quarterly macro-economic planning. In addition to fiscal policy strategies, are the current monetary policy tools in place; the central bank rate (CBR) and the cash reserve ratio (CRR) tools among others utilized to date to control interest rates and anchorage of inflation by the central bank of Kenya (Were et al., 2014). Their sustainable implementation by monetary authorities is believed to have had a desirable impact in monitoring the inflation and lowly containing the impact of domestic shocks. In most economies, the extent of such inflation damaging effects depend largely on the readily established institutional and structural economic arrangements (Gil-Alana \& Mudida, 2017; Gokal \& Hanif, 2004). Thus, this paper scrutinizes the relationship between unemployment, output and inflation, and their impact on the economy together with determinants of inflation for the period the state has largely been embracing inflation targeting measures through resilient fiscal and monetary measures, and fostering economic diversification (KER, 2017). 
In Kenya, previous studies have examined the inflation scenario. Durevall and Sjö (2012) scrutinized the determinants of inflation uncertainty for Ethiopia and Kenya on an error correction model (ECM) from 2000 to 2011. They used global food prices, exchange rates, surplus monetary supply and local agriculture as some of the variable sources of inflation volatility. From their results, similar drivers accounted for inflation. In the short term, monetary supply and agricultural shocks accounted for inflation while global food prices and exchange rates dominated the long run effects. They noted, the existent anti-inflationary policies were still infeasible hence need for sustainable policies. Our paper evaluates the extent of feasibility in the backdrop of perceived anti-inflationary policies and intensified adoption on an available up to date dataset. Roseline Nyakerario Misati (2012) scrutinized the feasibility of fiscal policy adoption in Kenya based on vector autoregressive (VAR) and granger causality framework through monetary policy inflation analysis. Their results noted that unlike exchange rate, monetary policies greatly controlled prices and output. They posited the need for fiscal policy variable inclusion in monetary policy planning with great emphasis on price level hypothesis. In addition, Kenya needed not to adopt ant-inflationary policies to stabilize inflation. However, their study failed to consider supply side shocks whose effects greatly influence the economy to the long run, notwithstanding, the country imports a considerably large proportion of commodities with oil commodity as major good (KER, 2017) than it exports thus prone to foreign shocks. For instance, according to KER (2017), net export contributed close to $-8.75 \%$ to output in 2016.

Mutuku and Ng'eny (2014) studied the effects of inflation and other macro-economic variables on the Kenyan equity market from 1997 to 2010. Using the vector error correction (VECM) framework, results noted, inflation negatively influenced the stock market. They posited stringent monetary policies be adopted to mitigate inflation. Our case, we objectively scrutinize the relationship between output, unemployment and inflation, and influence of unemployment and output in the inflation dynamics, an errand empirically deserted for Kenyan case.

Misati and Munene (2015) investigated the impacts of second round pass through effects of food prices on inflation using dataset from 1997 to 2012 on gap models and Phillips curve. Results noted 2 main significant pass through impacts. First, by gap model, the effects influenced overall inflation. Second, by Phillips curve, local pass through effects influenced both core and headline inflation by 0.49 and 0.38 respectively while global effects influenced headline and core inflation by 0.09 and 0.08 respectively. They posited headline inflation be core measure of inflation while monetary supply significantly anchors inflation expectations. This paper investigates the impact of employment and output to inflation and their relationship given their critical impact on development. We adopted the less volatile annual average rate of inflation that best represents inflation measure.

A key input of the paper is that it accounts for inflation equation and relationship to economic-growth and circumstances for the period tight monetary and fiscal policies have been implemented to stabilize domestic shocks. However, few existing studies have incorporated mainly domestic food prices and agriculture shocks while they have deserted unemployment contribution to inflation (output) relations and the detrimental influence of import shocks. This paper fills the gap by integrating unemployment into the mix and oil prices that capture effect of global and import shocks to reveal the detrimental effects of supply side shocks to inflation and unemployment. To obtain economically and empirically significant relationship, we investigated the situation on the Phillips curve structure, an errand, if any studies, to the best of research, have not yet empirically ventured the pathway given the demand to justify the level of the relationship.

Additional impact is, we used monthly data up to the most recent period and with full variable observations, unlike yearly data by most researchers in the area, a depiction of the possibility to explicitly investigate the inflation-unemployment influences on a short-time captured dataset and yield consistent results that depict the Kenyan case. Furthermore, and as previously noted, previous studies have explicated the relationship either using the ARDL, VECM, VAR or Granger causality and failed to address contemporaneity as cases where inflation and monetary policies have been involved. This paper addressed this problem blending to novelty; we used the two stage least square (2SLS) where we modelled 2 main equations models while accounting for endogeneity problem to ensure consistent and unbiased estimates. The models that were then instrumented differently, and with variable instruments, were diagnosed for consistency and contrasted for the best model that internment the shocks to the inflation dynamics. We posited three critical findings. First, unemployment significantly trades off with both inflation and output, and so does output-inflation, however, at relatively low magnitudes. Secondly, the rational inflation expectations and unemployment rate significantly drive the observed dynamics unlike for output. Thirdly, supply side shocks best destabilize price steadiness compared to monetary shocks. However, this does not deny fiscal policy strategist the opportunity to stabilize an optimal inflation to sustain nominal prices. In fact, they are at stake of containing both domestic and imported shocks through more feasible investment and economic policies. 
The remainder of the paper is structured as follows; the next section reviews the progressive evolution of the Phillips curve until its development in a market format with inflation expectations. Sections 3 divulge the data and methodology while 4 discuss the results and analysis respectively. Section 5 concludes and recommends from the results.

\section{Evolution of the Phillips Curve}

Macro-economic policy makers would wish for a stable inflation and unemployment in the backdrop of high economic growth. However, their wish yields to a confounding expectations. That is, if fiscal and or monetary policies are implemented, the boosted economic and industrial activities facilitate aggregate supply as firms hire more employees. Alternatively, if the policies have negative and demeaning impacts, the economy slides along the short-run aggregate supply curve to positions of price instabilities. Consequently, the demeaned economic growth results to decreased demand of inputs, investments and business activities as firms refrain from employment. This relationship is best explicitly explained by the Phillips (1958) curve, that was experimented on a UK economy and confirmed by Samuelson and Solow (1960) on the US economy. That is, higher employment could be achieved at higher inflation and vice-versa. Nevertheless, the stagflation in the US and OECD in late 60s couldn't be explained by the curve attracting critics (Friedman, 1995; Lucas, 1973; Phelps, 1968) that is, it was best effective in the short run, but, in the long run, structural unemployment persisted at full employment economy level. Accordingly, some economies at higher inflation could experience both low economic growth and low employment, an intuition of the denting effect of price stability to regulate employment. This saw the modification of the curve to NKPC, which, since then has widely been embraced as the cornerstone to scrutinize inflation-real economic activity connection. Categorically, it is widely adopted in the central banks to aid fiscal policy planning and price adjustments. In addition, the role played by the expectations in shaping inflation provides a substantial platform for the varied specifications of the curve which chains analysis and implicative effects of the resulting relationship. (Behera, Wahi, \& Kapur, 2018; Bhattarai, 2016; Xu, Niu, Jiang, \& Huang, 2015).

\subsection{Price Adjustments}

In a monopolistic market environment, policy makers are constrained from setting prices regularly in response to innovations affecting their smooth operations. As a result, and with respect to Calvo (1983), there exists a section $(\theta)$ of firms that rarely adjust their prices, $(1-\theta)$ are price elastic with the mean time $\left([1-\theta]^{-1}\right)$ over which the price is adjusted irrespective of the last period. On the other hand, those firms that operate on a sticky price baseline operates a backward price $\left(P_{t-1}\right)$ and an optimized price $\left(P_{t}^{o p t}\right)$ for the price adjusting entities as per Galı and Gertler (1999). As such, the anonymously consented (aggregate) price level $\left(P_{t}^{a}\right)$ is a function of past and optimized prices as denoted by Eqn. (2) (Clarida, 1990).

$$
p_{t}^{a}=\theta p_{t-1}+[1-\theta] p_{t}^{o p t}
$$

Conversely, most forward looking firms that evokes price elasticity $\left(P_{t}^{o p t}\right)$ would like to optimize their returns which is a function of the discounted factor $(\beta)$ and expected nominal marginal costs as in Eqn. (3). $E\left\{m c_{t+i}\right\}$ is the level of marginal cost of a firm which in most cases, proxied by elements of real economic activity e.g. output or unemployment.

$$
p_{t}^{o p t}=[1-\beta \theta] \sum_{i=1}^{\infty}(\beta \theta)^{i} E\left\{m c_{t+i}\right\}
$$

\subsection{The New Keynesian Phillips Curve}

In the event rational consumers and firms interact as in a monopolistic market, the pricing system is consequently staggered. Thus, the entities embroil all the information they know as expectations to justify observed inflation. With respect to the NKPC, observed dynamics is thus a harmonization of the aggregate price $\left(P_{t}^{a}\right)$ and optimized price $\left(P_{t}^{o p t}\right)$. Combining equation (2) and (3) in a Calvo (1983) format, yields the inflation Eqn. (4).

$$
\pi_{t}=\lambda m c_{t}+\beta E\left\{\pi_{t+1}\right\}
$$

From the equation, the structural parameter $\lambda=[1-\theta][1-\beta \theta] \theta^{-1}$ is a function of price stickiness and the discount factor due to price adjustment frequency and price optimization between the firm and the consumer. The inflationary dynamics is a function of marginal cost (as the major determinant) and inflation expectation from a market configuration where inelasticity in wages and consumer prices are the norms. 
If the agents of Eqn. (4) are unrestricted, Kajuth (2012), and Chu and Shane (2017) argued, there exists highest odds of unlimited choices between the rational and adaptive inflationary expectations of inflation. In most lower-, and lower middle- income countries, the impact of global shocks have depicted detrimental bearings to the economy. In addition, a substantial portion of these countries commodities are imported while agriculture plays significant role in their exports. This has exposed these economies as highly vulnerable to foreign shocks so that, economic agents are highly expectant in price settings. If the structural parameter $(\theta)$ progressively approaches triviality due to the increasing volatility in price optimization, then Eqn. (2) inevitably becomes forward looking, hence, Eqn. (4) is a function of the forward-looking inflation expectations and marginal cost.

\section{Data and Methodology}

\subsection{Data Set}

The study utilized monthly data from 2006:M01 to 2016:M16. The variables include oil consumption, net export, real GDP, monetary supply, inflation rate and unemployment rate. Oil consumption refer to the total petroleum fuels consumption in ' 000 metric tons, net export as the log difference between export and imports all by broad economy, monetary supply has been aggregated as broad money, money and Quasi money and expressed as a percentage change in millions of Kenya shillings (Kshs). Real GDP is expressed in Kshs millions and inflation as the annual average aggregated as the percentage CPI change from the equivalent month of previous year. All variables except, inflation rate and real GDP from the central bank of Kenya website and unemployment from the World Bank database, they were extracted from the statistical abstracts at the Kenya National Bureau of Statistics website. Due to lack of monthly observations, unemployment and real GDP series were interpolated to correspond the timings. We selected the variables partly due to consistency of data availability and majorly based on the objective of this paper. Unemployment and output (as GDP) constructed the marginal cost on the Phillips curve while oil consumption, net export and monetary supply were purposeful to capture the shocks in the inflation equation. We preferred the annual rate of inflation to year on year (yoy) measure due to its relatively less volatility to the thrilling off price innovations that have been accounted by the averaging method adopted to compute the measure. Otherwise, CPI measure alone is highly volatile as it captures the highly vulnerable food prices off shocks, which makes the measure uncorrelated with economic growth. As such, annual average rate of inflation measure best fit to model the relationship between inflation and marginal cost.

In the next step, we investigated the inflation behavior with its monthly time plot in figure 1 for the period $2006 \mathrm{M} 01$ to $2016 \mathrm{M} 12$. The average of the series is at $8.73 \%$, which is $3.73 \%$ greater than the central banks' target. Since 2006, an alternate pattern of inflation and disinflation can be observed. At the onset, the series is seen trending upward corresponding partly to food prices and agricultural shocks in the previous years to peak $15.3 \%$ in $2006 \mathrm{M} 03$, and gradually start to deflate through $5.7 \%$ target in 2007M07 to $4.3 \%$ in 2008M12. From this point, the steep accession is a response to the mixed economic instabilities that rocked the country; political instabilities, agricultural shocks and global oil price shocks so that inflation peaked high again in 2010M04 at $16.7 \%$. Fiscal policy strategist in turn responded by tightening monetary policies and macroeconomic models and intensified institutional and economic diversification that saw inflation trend downward and below the central banks 5\% target in 2011M2 and 2014M08. Since then, inflation trended upward gradually to $7.5 \%$ peak in 2015M05. Onwards, the trend has been downward; an implication of the positive influence of some of the inflation targeting policies adopted as gradually materializing.

Figures 2 to 5 are the plots of inflation, unemployment, monetary supply and net export. Contemporaneous correlation seem to materialize in figures $4-5$ while in 2-3, inflation-unemployment and inflation-output are contemporaneous up to around 2010M07, after which a confounding relationship is evident. However, from mid-2009, the movement between output and unemployment concurs with the Phillips curve. Oil consumption and monetary supply also moves together until 2015. Since then, they are unrelated. In figure 6, the relation can be alluded to an economic environment where monetary authorities work hard to sustain inflation as shocks due to upward trending oil component pulls and push away inflation from the fiscal authority's target. In the end, import shocks win to trend inflation relatively higher than expected. The left scales in figure 2, 3, 5 and 6 represents to inflation rates while the right scales in figures 4 and 7 denotes to unemployment and monetary supply. All variables are graphed in their logged state except monetary supply.

\subsection{Methodology}

Herein, we developed the equations used to scrutinize the trade-off and inflation drivers. We modeled both the trade-off Phillips curve and NKPC curve formats to elucidate whether the Phillips curve still holds. The aim of the trade-off is to scrutinize the correlation and effects between inflation (unemployment) and real economic activities, which is vital in fiscal policy planning, setting market prices and addressing unemployment. We used 
the ordinary least square regression with variance covariance robust estimates objectively to attain consistent estimates of the parameters in constructing the trade-off relationship. We proxied $m c_{t}$ using unemployment, and output on a log-log model for Eqn 5-7. All through, we utilized stationary series in the regressions and presented the results in tables 2,3 and 4 in that order.

$$
\begin{gathered}
\ln \left(\pi_{t}\right)=k_{1}-\alpha_{1} \ln u_{t}+e_{1 t} \\
\ln \left(\pi_{t}\right)=k_{2}-\alpha_{2} \ln G d p_{t}+e_{2 t} \\
\ln \left(g d p_{t}\right)=k_{3}-\alpha_{3} \ln \left(u_{t}\right)+e_{3 t}
\end{gathered}
$$

In the next step, we constructed the inflation equation on the NKPC format purposefully to identify the relevance and impact of inflation expectations and marginal cost $\left(m c_{t}\right)$ in accounting for the observed inflation. We followed Chu and Shane (2017) and Kajuth (2012) style and constructed Eqn. (8). Arguably, from their idea, and in open economy market structure, inflation expectation to the price setters are unrestricted amidst past and future inflationary experiences. Empirically, $\pi_{t}^{e}$ is modelled either from unobserved inflation (Kajuth, 2012), surveyed based expectations or past experience (Basarac, Skrabic, \& Sorić, 2012; Zhang, Osborn, \& Kim, 2009)

$$
\pi_{t}=\phi \pi_{t}^{e}+\lambda\left\{m c_{t}\right\}+\varepsilon_{t}
$$

Equally, as for the lower middle income economies, in Kenya, the staggering pricing system is the norm of the market while, the effects of foreign shocks due to import commodities are the most inevitable. This makes the frequency of pricing system forward looking. Thus, the one-time forward of observed inflation proxied the inflation expectations in Eqn. (8) due to lack of surveyed data on inflation perceptions. Arguably, surveys bear own detrimental limitations. They not only forego public perceptions at expense of expert forecast but also not a typical representation of the expectation atmosphere. Thus, the forward inflation was also purposeful to capture price optimization effects and dynamism in the equation. The proxies to $\pi_{t}$ is the observed monthly annualized average inflation series while $m c_{t}$ is unemployment and output (GDP).

Using the 2SLS technique on Eqn. (8), we captured oil consumption (oilc), net export (xn) and monetary supply as the endogenous variable purposeful to internment the shocks to inflation without forgetting that Kenya is at risk of foreign factors with imports playing a major role in capital outflows. Oil fuels are part of the biggest proportion of imported commodities.

We estimated 2 models of Eqn. (8), using 2 variant proxies of $m c_{t}$ with (out) relaxing some of the instrument in each case. The instruments included lags 2-4 of monetary supply and net export, and of output. Unemployment and GDP for models 1 and 2 respectively constituted the $m c_{t}$. In each model, we instrumented oil consumption, monetary supply, and net export to have 3 scenarios. Each scenario finally estimated pairwise: with and without monetary supply lags in the instruments. This was purposeful to elucidate the best endogenous variable that best relaxes the innovations to drivers of inflation, and for relative comparison with domestic shocks. We estimated the 2SLS with robust variance-covariance estimates than benchmark OLS. The latter is argued to produce inconsistent and biased estimators under endogeneity misfortunes. Table 4 presents these results.

We chose the 2SLS over other mixture stationary techniques specifically due to a number of reasons. (1) Its ability to account for endogeneity problem as some of the instrumented variables critically drive observed inflation dynamics, an aspect we developed interest to explore, (2) the variables as in figure 2 to 5 embraced contemporaneity for some or whole period prompting our decision, and (3) measurement errors that might be due to data omission and aggregation. Since monthly data best models the business cycle, not all variables could be found aggregated in such format. In addition, due to a steady gradual growth in some of the proxies of $m c_{t}$, problems such as heteroscedasticity and autocorrelation might be inevitable forcing us to embrace the 2SLS. We countered aforementioned misfortunes by appropriate data transformations, laggings, and truncating the time span. We selected data set from 2006 to 2017 due to missing monthly observation for some variables for period before 2006 and after 2017. The fact that our dataset constituted a $T>N$, prompted the 2SLS preference to the generalized methods of moments (GMM) and the results tabulated in table 5.

Progressively, we executed diagnostic checkups for each model and presented this results in table 6 for purpose of contrasting on the best model to account for the dynamics.

\section{Results and Analysis}

Stationarity test is a crucial pre-condition for analysis of the trade-off. With regard to table 1, we presented unit root test for $\pi_{t}, U_{t}, G d p_{t}, X n_{t}, M s_{t}$ and Oilc $c_{t}$ by both ADF and PP. $X n_{t}, M s_{t}$ and Oilc $c_{t}$ portrayed stationarity at level by both ADF and PP while $U_{t}$ and $G d p_{t}$ attained stationarity after first differencing and hence are I(1). Conversely, $\pi_{t}$ displayed confounding tests. It was stationarity at level and at first difference by $\mathrm{ADF}$ and $\mathrm{PP}$ respectively, which we attribute to the test equations' specifications. 
In reference to tables 2-4, the respective regression outcomes presented due to robust least square have robust standard errors and consistent relative to OLS. All the 3 models have their joint probability significant at 5\% level. In table 1 and 2, unemployment and output trade negatively with inflation to concur with the trade-off curve. Thus, a $1 \%$ increase in unemployment and output would decrease inflation by $2.09 \%$ and $0.08 \%$ respectively. Output also trades-off significantly with unemployment that, a $1 \%$ increase in output would decrease unemployment by $0.02 \%$. The elasticities $2.09 \%, 0.08 \%$ and $0.02 \%$ are relatively low and significant accrediting to the anti-inflationary and tight monetary policies by central banks that have underpinned inflation. Also, the adoption of public trust and transparency awareness system by fiscal policy makers and central banks towards oversighting of financial systems and tools, and the adjusted economic structures in tracking macroeconomic variable performance have substantially embodied.

In the labor market, inflation-unemployment trade-off denotes to a condition where the growing economy coincides with inflated prices alongside high demand for labor. The prevailing high wage rates attracts more labor force as unemployment retracts. Conversely, as the economy recedes, job creation stagnates against the high supply of labor force whose reservation wage rates are very high. Employers seize employment due to the high procurement costs and marginal cost involved causing unemployment to trade upwards. Results concur with Bhattarai (2016) in OECD countries for the period 1990q1-2014q4. The underlying unemployment level is relatively lower at $0.89 \%$ than the average rate for the whole study period at $11.5 \%$, an indication of the decreasing labor imperfections and fiscal policy feasibility. Results also denotes that if the economy achieve its full potential, then low unemployments can be achieved through high adjustments in inflation and vceversa. However, such policies, although effective with fiscal strategist, they would harm the unemployed and low income earners denting their livinig standards.

In a sustainable economy, unemployment-output trade-off as in our study, it is at $0.02 \%$, alludes to the progressive economic developments with improving infrastructural, social and institutional foundations so that the relatively lower inflation rates or anchored towards the central banks' target, have promoted growth. Consequently, this has reduced the interbank rates and lending rates for commercial banks. In turn, capital accumulation is increased, promoting sectorial economic development, employment and quality of livelihoods. However, in case of domestic policy shocks, they are absorbed within the foundations leaving unemployment to trade-off at low level and normally. Similar trade-off is by Tesfaselassie and Wolters (2018) for US and Europe that high growth reduced unemployment. Results also noted that at higher economic activities, they facilitated inflationary backdrop that pushed high the mark up prices and firms raised their advantages in job creation that demeaned unemployment.

On the other hand, inflation and output trades off so that inflation is reduced by $0.08 \%$ when output grows by $1 \%$ rate. We suspect it to the low levels of inflation facilitated due to tight monetary and fiscal policies, and the institutional and infrastructural developments largely adopted. This has seen more job opportunities created and alleviated poverty levels. Comparable studies that noted the negative relationship include Nyongesa et al., (2017) for East Africa panel with weak effects of inflation on output.

In table 5, results of the 2SLS are presented. M1 and M2 denotes to two models where unemployment and GDP have been used as the main inflation drivers, and each instrumented on oilc, $m s, x n$ and finally, on a combination of both yielding versions (a)-(h). Versions $\mathrm{a}, \mathrm{c}$, e and $\mathrm{g}(\mathrm{b}, \mathrm{d}, \mathrm{f}$ and $\mathrm{h}$ ) regressed by including (excluding) monetary supply lags in the instruments.

To start with, both models' joint F- statistic at $1 \%$ are significant. Inflation expectations are also significant, validating the rational looking information in the inflation equation. In the second column, where are the coefficients of unemployment and output, equation (a) to (h) in the first model are significant at 5\% a confirmation, unlike output, unemployment best drives inflation. In addition, the co-efficients of the constants of equations (a) to (h) in M1 are significant. This signify cruciality of the underlying rates of unemployment. In M1 (a), (b) and M2 (a), and where singly instrumented, oil consumption is significant unlike monetary supply. However, when combined and instrumented, oil consumption in M1(h) is the only significant. This concurs that, oil consumption best clips the shocks to observed dynamics compared to monetary supply and net export. Net exports, on the other hand, are argued to rely on the level of the dynamics so that they are demeaned at high inflation causing trade deficits, while it has overridden imports at low inflation. The situation best characterizes the Kenyan case where, for the current decade, foreign commodities have had an established expansive market basement, while a shock in their supply, has hurled uncertainties and distorted the pricing system with negative impacts on the living standard. As noted formerly, and as the most imported commodity in the country, petroleum fuels are a major source of energy for almost all the sectors of the economy. Thus, a shock in supply translates across all sections and diffuses to the long run. Models (c) to (h) in both M1 and M2 and elsewhere 
$m S$ has been utilized, it's evident, monetary supply is inevitably insignificant to be instrumented in the inflation equation. This is because fiscal policy shocks are mainly short-termed and perceived to effect a subset of the economy for instance the financial and banking sector, and commercial sector unlike for net export and oil that innovates all sectors of economy until the long run.

In table 6, diagnostic tests for individual models are presented for purpose of comparison and selection of best model that account the inflation dynamics. The table bears: endogeneity test for oil consumption, net export and monetary supply, sufficiency of the instruments modelled in the initial stages and test for the strength of correlation between endogenous variable to the drivers of inflation.

According to table 6, both the robust score and Durbin statistics in equations M1 rejects the null hypothesis of exogeneity unlike M2, a depiction; monetary supply, net export and oil consumption correlate with the drivers of inflation. In the middle column, the robust F-statistic in M1, M2 and Eigen statistic in M2(a) and (b) suggest, lagged output, monetary supply, current inflation and net export used, indeed, are strongly correlated to monetary supply, net export and oil consumption for the inflation equation. In the third column, the null hypothesis is accepted by both Score- $x^{2}$ and Sargan- $x^{2}$ tests in both M1 and M2 except for M1 (c), (g) by Score, and (c), (d) by Sargan test. Thus, the equations correctly been parameterized.

For comparison purposes, and based on the significance of the equation parameters, we carry forward M1 (a - h) from table 5 purposefully to diagnose the best inflation equation. In addition, and objectively to determine the strength of correlation between oil consumption, net export and monetary supply to the drivers of inflation. Since robustness of the standard errors have been accounted and all the models correctly parameterized, the minimum Eigen and Score- $x^{2}$ statistics constitutes our elimination framework. As such, we expect to go by rejection of the null by exogeniety and acceptance by override for Score- $x^{2}$ that, however, eliminates the significant contributions of net exports and monetary supply shocks (in M1 (d) to (f)), specifically under weak instrumentation. Consequently, we expect a relatively strong (if not weak) instruments that are endogenous. However, model 2 has formerly been overruled hence the trivial input of output to drive inflation. As such, equation (a) and (b) by minimum Eigen statistics rejected the null hypothesis at 5\% and hence have strong instruments. Intuitively, the instruments in both equations denote strong correlation with oil consumption unlike monetary supply and net export. In sum, equation M1(a) and (b) depict correct instrumentation and parameterization.

From the diagnostics, M1(a) and (b) thus depict unemployment and inflation expectations best explains the observed dynamics in the backdrop of import shocks unlike if domestic. In addition, in the models, it's evident that oil consumption best internments the dynamics under strong foreign shocks unlike monetary supply and net export that were insignificant, Thus, oil commodity best captures the economic shocks due to its varied and vital utility in many sectors of the economy.

We divulge, according to M1(a) and (b) the current inflation dynamics is a function of unemployment and inflation expectations (the rational effect) in the backdrop of strong foreign shocks. The pair (a) and (b) was estimated with oil consumption as the instrumented variable. However, (b) had monetary supply lags eliminated from its first stage equation. Still in table 6, and comparing the Eigen statistics of the best out of the pair, (a) and (b) have their statistics at 20.58 and 31.56 respectively. Statistics for the later best rejects the null of weak instruments at the 2SLS relative bias unlike the former. Hence, model (b) predominates (a) to account the inflation dynamics. Eqn. 9 depicts their inflation equations with parameters denoting the elasticities to inflation.

$$
\begin{aligned}
& \ln \pi_{t}=0.60+1.01 \pi_{t}^{e}-0.26 u_{t} \\
& \ln \pi_{t}=0.63+1.01 \pi_{t}^{e}-0.28 u_{t}
\end{aligned}
$$

From Eqn. 9, we conclude, foreign innovations best shock the inflation dynamics than monetary policies. In both, inflation expectations and unemployment, respectively, inflates and deflates the observed inflation on average by $1.01 \%$ and $0.27 \%$ in that order. Herein, the inflation-unemployment trades-off (by ceteris paribus) confirming the validity of Phillips curve. As noted earlier, (b) had monetary supply lags frozen from its instrumentation, it is clearly depicted, observed inflation to some case, is independent of liquidity shocks. We advance Eqn.9, however, with (b) as the best chosen model to account for the dynamics due to its relatively stronger instruments so that, oil consumption that innovates the system, strongly correlate with foreign and other external shocks that determine petroleum fuels supply and pricing. This clearly elucidate the relative importance of supply (foreign shocks) than demand shocks in addressing the dynamics in the country. This has conferred the price-setting behavior as rationally looking. These results concur with those from Nguyen, Dridi, Unsal, and Williams (2017). They investigated the inflation dynamics in Sub-Sahara Africa with Kenya included using both supply side and demand side proxies. Their results illuminated the inconsequential effect of fiscal policies in the inflationary 
process, which is a true replication of the Kenyan setting. Consequently, the significance of the expectations in Eqn. 9 depicts to the risky staggering nature of prices that are highly determined by the forward inflation shocks as an inevitable foundations of the existing dynamics.

The insignificance of demand side shocks exhibits the progressive significance achieved by the fiscal and monetary authorites in adopting and implementation of tight monetary and fiscal planning policies that have managed to considerably subside local shocks. However, we concur with Durevall and Sjö (2012) that, not much have been done to contain supply side shocks since the country does import considerably large proportion of goods and service (with oil as one of the major imports commodity) than it could export resulting to massive capital outflows. This has greatly induced imbalance in trade making the economy successptible to foreighn shocks.

\section{Conclusion}

This paper investigated the validity of the trade-off Phillips curve and determinants of inflation for the post 2000 period in which inflation targeting policies been intensively embraced by fiscal and monetary authorities to determine their level of feasibility as one of the objectives. We used dataset from 2006:M1 to 2016:M12 to expedite the trade-off by robust least square and inflation equation by contrasting the 2-SLS on 2 different measures of marginal cost with 3 differently instrumented shocks; a supply side and demand side for the case of NKPC.

Results depicted a significant trade-off between inflation-unemployment, inflation-output and output-unemployment. As such, inflation reduced by $2.09 \%$ and $0.08 \%$ when unemployment and output respectively increased by $1 \%$, while a $1 \%$ increase in output demeaned unemployment by $0.02 \%$. In the inflation dynamics, unlike output, unemployment and inflation expectations posed significant drivers of inflation observed. Diagnostics tests revealed that inflation dynamics observed is a function of the rational inflation expectations and unemployment in the background of foreign than local shocks. The insignificance of monetary shocks denotes how substantially successful fiscal policies and other anti-inflationary measures been implemented in price stability although more need to be done to suffice the long term shocks. We as well credit the progressive economic developments undertaken to alleviating structural, social and institutional foundations. These has facilitated expansion in output and receded inflationary powers, so that, in case of demand shocks, they are definitely absorbed within the foundations leaving unemployment to trade-off normally. Also, the recently established mass-awareness informative systems of the economic status, management of economic tools, and building of public trust and expectations that policy agents and central bank have the ability to sustain price stabilities. The whole interaction process has impelled inflation and unemployment to trade at considerably low magnitudes.

To the literature and novelty, this paper expedited the relationship between unemployment, inflation and output, their impacts, and the role of unemployment and inflation expectation in price determination, an errand to the best of our research, has empirically not yet investigated. We used up to the most recent full monthly dataset unlike other studies with yearly. In addition, previous studies have explicated the inflation equation either using ARDL, VECM, VAR, granger causality, among others. This paper used the 2SLS, which unlike aforementioned techniques, best captures variable endogeneity and contemporaneity for case with large time domain.

The main findings by this paper entailed, first, the Phillips curve still holds in the Kenyan case although at low trade-off magnitude indicated by the relatively lesser coefficients. Secondly, inflation expectations and unemployment are the main determinants of the observed dynamics in the backdrop of oil shocks. As such, in case of import shocks, the economy would severely be deteriorated to the long run unlike with the short termed domestic shocks (that were insignificant) due to their containable ability by fiscal authorities.

Although the CBK through its macro-economic policies seem to have contained monetary and domestic innovations, little have yet materialized with anchoring long-term shocks due to oil commodity and other import shocks that are normally exogenously determined. This paper recommends that intensive implementation of tight and feasible fiscal policies that would foster robust price stabilities, strong investments and macroeconomic diversification to reduce influence of import and other supply shocks. The energy sector should promote policies for renewable energy technologies to reduce over reliance on oil fuels and other commodities that are largely imported. Since the country is a foreign trade mogul with high trade imbalances, this, would reduce large capital outflows, cushion the Kenya shilling against devaluation on the international market. Partially to natural shocks in agriculture, drought resilient technologies and increased feasible irrigation investments should be adopted in order to boost supply and net export. Despite the limited dominance of monetary shocks in the inflation equation, also revisiting the existing inflation targeting strategies and their intensification are inevitable for long run price 
stabilities. If the above policies are implemented, plausibly would reduce, the denting influence of inflation expectations in price setting and inflation on economic growth and employment.

\section{Acknowledgements}

I sincerely acknowledge the authors for their concerted efforts towards the paper and the anonymous referees for their constructive comments. As the norm, the usual disclaimer applies.

Table 1. Unit root test

\begin{tabular}{cllll}
\hline & & level & $\Delta$ & \\
& ADF & PP & ADF & PP \\
\hline$\pi_{t}$ & {$[-6.88]^{* * *}$} & {$[-2.06]$} & - & {$[-2.76]^{*}$} \\
$U_{t}$ & {$[-1.47]$} & {$[-1.91]$} & {$[-11.45]^{* * *}$} & {$[-11.35]^{* * *}$} \\
$G d p_{t}$ & {$[-2.21]$} & {$[-0.77]$} & {$[-11.57]^{* * *}$} & {$[-11.63]^{* * *}$} \\
$X n_{t}$ & {$[-9.72]^{* * *}$} & {$[-6.93]^{* * *}$} & - & - \\
$M s_{t}$ & {$[-11.34]^{* * *}$} & {$[-6.49]^{* * *}$} & - & - \\
$O i l c_{t}$ & {$[-6.52]^{* * *}$} & {$[-3.82]^{* * *}$} & - & - \\
\hline
\end{tabular}

***,* Significance at 1 and $10 \%$, [] denotes the t-statistics, $H_{0} \sim$ unit root present.

Note. 1) Test equation for $\pi_{t}$ at $1^{\text {st }} \mathrm{lag}, U_{t}$, and $O i l c_{t}$ was done at constant and trend while $X n_{t}$, Ms $s_{t}$ done at constant respect to the time plot characteristic. 2) ADF and PP refers to Augmented Dickey Fuller, and Phillips and Perron respectively.

Table 2. Regression of inflation on unemployment

\begin{tabular}{lll}
\hline & $C$ & $U_{t}$ \\
\hline$\pi_{t}$ & $0.89[53.18]^{* * *}$ & $-2.09[-4.80]^{* * *}$ \\
\hline
\end{tabular}

$\operatorname{Prob}(\mathrm{F}=23.04)=0.00 * * *, R^{2}=0.011$, White test $\left(x^{2}=2.56\right)=0.278, \mathrm{DW} ; \operatorname{Prob}(\mathrm{d}(2,131)=0.157$

Table 3. Regression of inflation on output

\begin{tabular}{cll}
\hline & $c$ & $G d p_{t}$ \\
\hline$\pi_{t}$ & $1.41[2.99]^{* * *}$ & $-0.08[-1.09]^{* * *}$ \\
\hline
\end{tabular}

$\operatorname{Prob}(\mathrm{F}=1.19)=0.29 *, R^{2}=0.02$, White test $\left(x^{2}=9.74\right)=0.00^{* *}, \mathrm{DW} ; \operatorname{Prob}(\mathrm{d}(2,132)=0.03 * *$

Table 4. Regression of unemployment on output

\begin{tabular}{ccc}
\hline & $c$ & $G d p_{t}$ \\
\hline$U_{t}$ & $0.001[0.81]^{*}$ & $-0.02[-3.46]^{* * *}$ \\
\hline $\operatorname{Prob}(\mathrm{F}=11.98)=0.00^{* * *}$, & $R^{2}=0.004$, White test $\left(x^{2}=1.20\right)=0.548, \mathrm{DW} ;$ Prob $(\mathrm{d}(2,131)=2.01$. &
\end{tabular}

Table 5. The 2-SLS regression

\begin{tabular}{|c|c|c|c|c|c|c|}
\hline M1 & $\begin{array}{c}\ln \pi_{t}=c+\phi \\
C\end{array}$ & $\lambda$ & $\phi$ & $\begin{array}{l}\text { Endogenous } \\
\text { oilc }\end{array}$ & Wald $x^{2}$ test & $R^{2}$ \\
\hline $\mathrm{a}$ & $0.60[-3.68]^{*}$ & $-0.26[-3.67]^{*}$ & $1.01[70.60]^{*}$ & $0.001[2.55]^{*}$ & 6036.8* & 0.97 \\
\hline $\mathrm{b}$ & $0.63[3.80]^{*}$ & $-0.28[-3.84]^{*}$ & $1.01[69.02]^{*}$ & $\begin{array}{l}0.001[3.25]^{*} \\
m s\end{array}$ & $5847.0^{*}$ & 0.97 \\
\hline $\mathrm{c}$ & $0.53[3.24]^{*}$ & $-0.22[-3.15]^{*}$ & $1.01[70.83]^{*}$ & $-0.004[-0.57]$ & $5944.5^{*}$ & 0.96 \\
\hline $\mathrm{d}$ & $0.53[3.19]^{*}$ & $-0.22[-3.09]^{*}$ & $1.01[68.11]^{*}$ & $\begin{array}{l}-0.004[-0.67] \\
x n\end{array}$ & $5718.8^{*}$ & 0.96 \\
\hline $\mathrm{e}$ & $0.80[2.77]^{*}$ & $0.39[3.57]^{*}$ & $1.00[58.90]^{*}$ & $-0.35[-2.65]$ & $3774.3^{*}$ & 0.95 \\
\hline $\mathrm{f}$ & $0.79[2.77]^{*}$ & $-0.35[-2.63]^{*}$ & $1.00[59.46]^{*}$ & $\begin{array}{l}-0.16[-1.33] \\
o i l c^{1}, m s^{2}, x n^{3}\end{array}$ & $3807.3 *$ & 0.96 \\
\hline $\mathrm{g}$ & $0.67[2.92]^{*}$ & $-0.30[-2.80]^{*}$ & $1.01[73.09]^{*}$ & $\begin{array}{c}0.001[1.43]^{1} \\
0.003[0.49]^{2} \\
-0.05[-0.42]\end{array}$ & $6067.0^{*}$ & 0.97 \\
\hline $\mathrm{h}$ & $0.50[2.14]^{\mathrm{a}}$ & $-0.23[-2.05]^{\mathrm{a}}$ & $1.02[62.45]^{*}$ & $\begin{array}{l}0.001[2.53]^{* 1} \\
0.011[1.10]^{2} \\
0.101[1.02]^{3}\end{array}$ & $5298.6^{*}$ & 0.96 \\
\hline
\end{tabular}




\begin{tabular}{|c|c|c|c|c|c|c|}
\hline \multirow[t]{2}{*}{ M2 } & \multicolumn{6}{|c|}{$\ln \pi_{t}=c+\phi \pi_{t}^{e}+\lambda \ln g d p_{t}$} \\
\hline & $c$ & $\lambda$ & $\phi$ & oilc & & \\
\hline $\mathrm{a}$ & $-0.29[-1.45]$ & $0.06[1.58]$ & $0.98[72.11]^{*}$ & $-0.001[-1.68]^{b}$ & $6541.3^{*}$ & 0.96 \\
\hline \multirow[t]{2}{*}{$\mathrm{b}$} & $-0.15[-0.87]$ & $0.03[0.91]$ & 0.98 [62.93]* & $-0.001[-0.82]$ & $7656.4^{*}$ & 0.97 \\
\hline & & & & $m s$ & & \\
\hline $\mathrm{c}$ & $-0.03[-0.35]$ & $0.01[0.44]$ & $0.99[77.13]^{*}$ & $0.002[0.36]$ & $6611.9^{*}$ & 0.97 \\
\hline \multirow[t]{2}{*}{$\mathrm{d}$} & $-0.03[-0.41]$ & $0.01[0.49]$ & $0.98[75.69]^{*}$ & $0.003[0.45]$ & $6644.3^{*}$ & 0.97 \\
\hline & & & & $x n$ & & \\
\hline $\mathrm{e}$ & $-0.04[-0.43]$ & $0.01[0.53]$ & $0.99[86.66]^{*}$ & $0.030[0.39]$ & $7792.1^{*}$ & 0.97 \\
\hline \multirow[t]{2}{*}{$f$} & $-0.05[-0.48]$ & $0.02[0.60]$ & $0.99[85.9]^{*}$ & $0.040[0.51]$ & $7762.8^{*}$ & 0.98 \\
\hline & & & & oilc $^{1}, m s^{2}, x n^{3}$ & & \\
\hline \multirow[t]{3}{*}{ g } & $-0.29[-1.48]$ & $0.06[1.60]$ & $0.98[65.13]^{*}$ & $-0.001[-1.52]^{1}$ & $7682.7^{*}$ & 0.95 \\
\hline & & & & $-0.002[-0.29]^{2}$ & & \\
\hline & & & & $-0.010[-0.10]^{3}$ & & \\
\hline \multirow[t]{3}{*}{$\mathrm{h}$} & $-0.10[-0.34]$ & $0.0[0.32]$ & $0.99[65.71]^{*}$ & $-0.001[-0.16]^{1}$ & $9950.1^{*}$ & 0.97 \\
\hline & & & & $0.002[0.13]^{2}$ & & \\
\hline & & & & $0.026[0.38]^{3}$ & & \\
\hline
\end{tabular}

${ }_{*, \mathrm{a}, \mathrm{b}}$ significance at 1,5 and $10 \%$, [] denotes the $\mathrm{t}$-statistics. In models $1 \& 2: \mathrm{b}, \mathrm{d}, \mathrm{f}$ and $\mathrm{h}$ was regressed with exclusion of monetary supply lags in the instruments list. Instruments list: lags 2 to 4 of monetary supply and logged GDP, and $1^{\text {st }}$ lag of net export respectively.

Table 6. Diagnostic checks

\begin{tabular}{|c|c|c|c|c|c|c|}
\hline \multirow{2}{*}{\multicolumn{2}{|c|}{$\begin{array}{l}\text { Endogeneity } \\
H_{0}: \text { exogenous variables }\end{array}$}} & \multirow[b]{3}{*}{ Durbin- $x^{2}$ statistics } & \multirow{2}{*}{\multicolumn{2}{|c|}{$\begin{array}{l}1^{\text {st }} \text { stage diagnostics } \\
H_{0}: \text { weak instruments }\end{array}$}} & \multicolumn{2}{|c|}{ Over-ide restrictions } \\
\hline & & & & & & \\
\hline M1 & Robust score $x^{2}$ statistics & & Robust F- statistics & Minimum Eigen statistics & Score- $x^{2}$ & Sargan- $x^{2}$ \\
\hline $\mathrm{a}$ & $8.01 * *$ & $8.00 * *$ & $20.77 * *$ & $20.58^{a}$ & 8.69 & 7.64 \\
\hline $\mathrm{b}$ & $10.11 * *$ & $12.72 * *$ & $31.43 * *$ & $31.46^{\mathrm{a}}$ & 3.06 & 2.13 \\
\hline $\mathrm{c}$ & 1.01 & 0.80 & $3.37 * *$ & 2.13 & $7.56^{* *}$ & $7.56 * *$ \\
\hline d & $0.93 * *$ & $0.78 * *$ & $2.03^{*}$ & 1.69 & 9.26 & $1.07 *$ \\
\hline $\mathrm{e}$ & $2.67 * *$ & $2.30 * *$ & $3.24 * *$ & 0.61 & 6.37 & 6.11 \\
\hline $\mathrm{f}$ & 2.61 & 2.13 & $4.61 * *$ & 1.09 & 3.88 & 4.02 \\
\hline \multirow[t]{3}{*}{$\mathrm{g}$} & $8.51^{* *}$ & $8.24 * *$ & $20.77^{*} * 1$ & 0.29 & $8.05^{*}$ & 7.38 \\
\hline & & & $2.03 *^{2}$ & & & \\
\hline & & & $3.24 * *^{3}$ & & & \\
\hline \multirow[t]{3}{*}{$\mathrm{h}$} & $13.69^{* *}$ & $13.58 * *$ & $31.43^{* * 1}$ & - & 0.76 & 0.53 \\
\hline & & & $3.37 *^{2}$ & & & \\
\hline & & & $4.61 * *^{3}$ & & & \\
\hline \multicolumn{7}{|l|}{ M2 } \\
\hline $\mathrm{a}$ & 1.31 & 1.02 & $8.19 * *$ & 2.41 & 4.21 & 1.27 \\
\hline $\mathrm{b}$ & 0.05 & 0.20 & $11.31 * *$ & 1.57 & 3.18 & 0.55 \\
\hline $\mathrm{c}$ & 0.01 & 0.01 & $2.71 * *$ & 1.56 & 6.25 & 3.37 \\
\hline d & 0.01 & 0.01 & $4.50 * *$ & 1.89 & 2.14 & 0.62 \\
\hline $\mathrm{e}$ & 0.19 & 0.10 & $3.33 * *$ & 0.58 & 5.31 & 3.25 \\
\hline f & 0.34 & 0.15 & $3.75^{* *}$ & 1.02 & 2.14 & 0.59 \\
\hline \multirow[t]{3}{*}{$\mathrm{g}$} & 1.710 & 1.22 & $8.19 * * 1$ & 0.53 & 4.42 & 1.17 \\
\hline & & & $2.71 * *^{2}$ & & & \\
\hline & & & $3.33^{* *^{3}}$ & & & \\
\hline \multirow[t]{3}{*}{ h } & 0.25 & 0.08 & $11.31 * *^{1}$ & - & 2.10 & 0.51 \\
\hline & & & $4.50 * *^{2}$ & & & \\
\hline & & & $3.75^{* *^{3}}$ & & & \\
\hline
\end{tabular}

** and *significance at 5 and 10\%, superscripts a, b, c and d denote 5, 10, 20 and 30\% significance respectively at the 2-SLS relative bias while superscript 1-3 denotes to oilc, $m s$ and $x n$ respectively. 


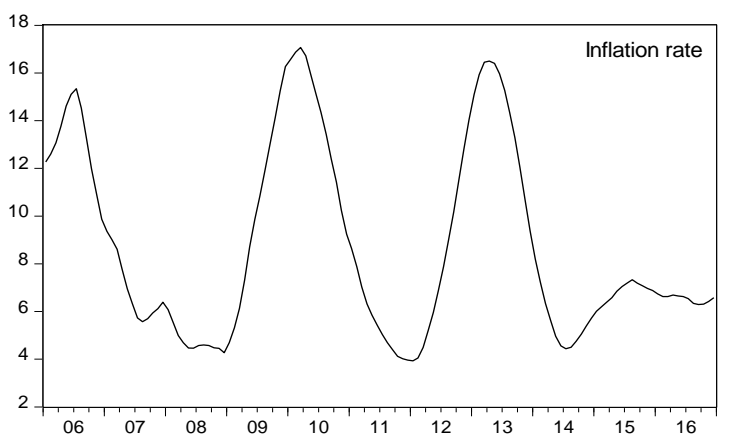

Figure 1. Inflation series

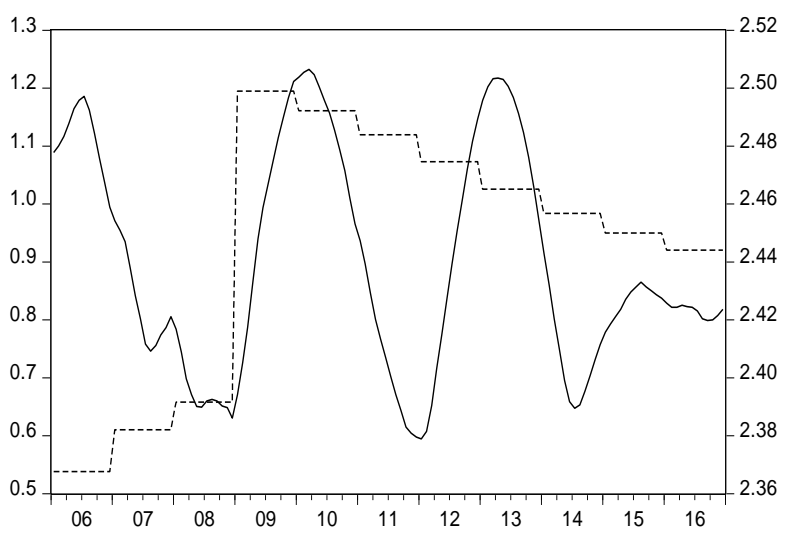

- Inflation rate ---- Unemployment rate

Figure 2. Plots of Inflation and Unemployment

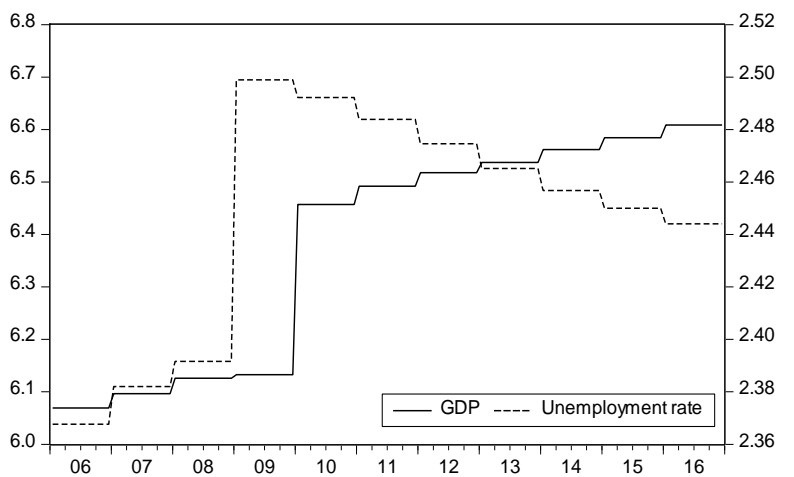

Figure 4. Plots of Output and Unemployment

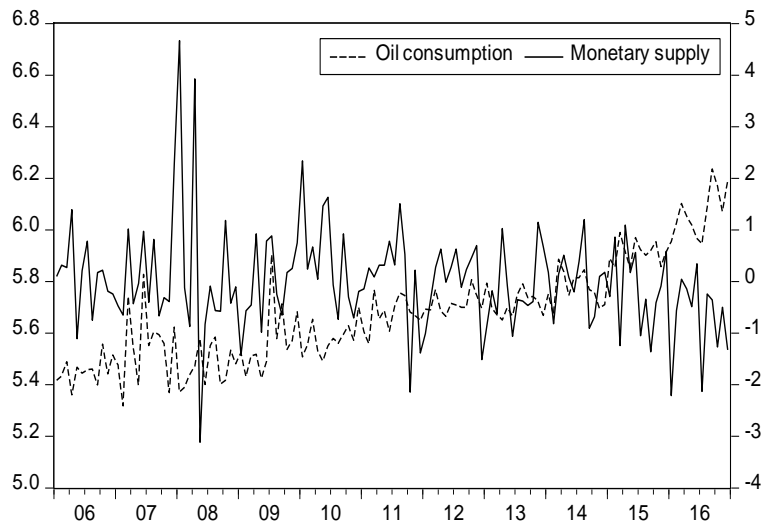

Figure 6. Plots of Inflation and Oil consumption

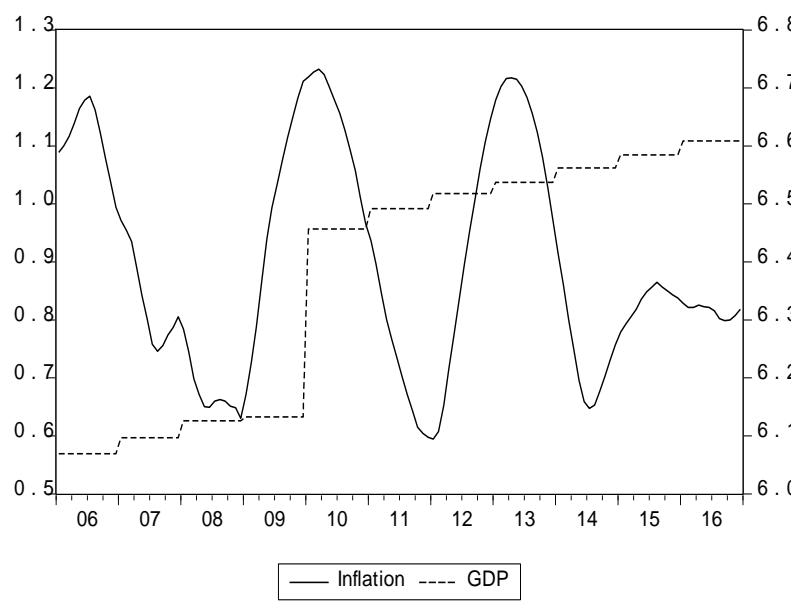

Figure 3. Plots of Inflation rate and Output (GDP)

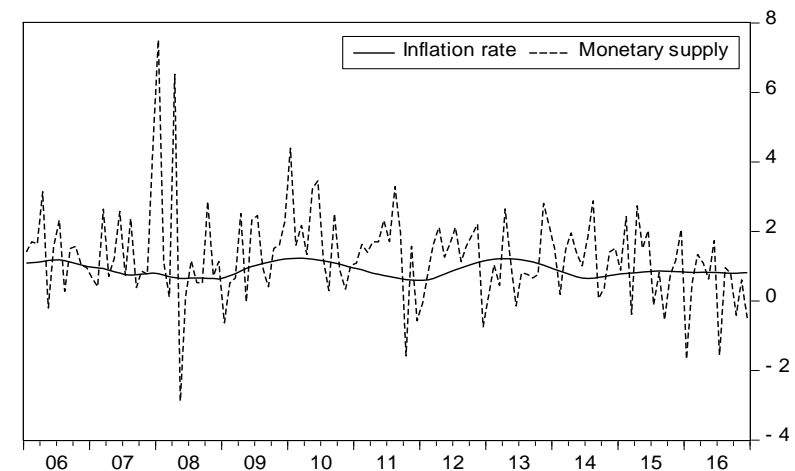

Figure 5. Plots of Inflation and Monetary supply

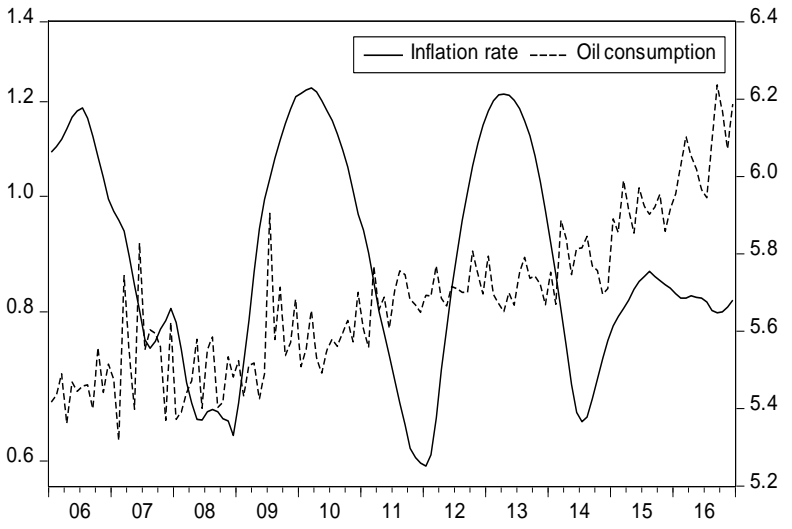

Figure 7. Plots of Oil consumption \& Monetary supply 


\section{References}

Basarac, M., Skrabic, B., \& Sorić, P. (2012). The Hybrid Phillips Curve: Empirical Evidence from Transition Economies. Czech Journal of Economics \& Finance, 61, 367-383.

Behera, H., Wahi, G., \& Kapur, M. (2018). Phillips curve relationship in an emerging economy: Evidence from India. Economic Analysis and Policy, 59, 116-126. https://doi.org/10.1016/j.eap.2018.06.001

Bhattarai, K. (2016). Unemployment-inflation trade-offs in OECD countries. Economic Modelling, 58, 93-103. https://doi.org/10.1016/j.econmod.2016.05.007

Calvo, G. A. (1983). Staggered prices in a utility-maximizing framework. Journal of Monetary Economics, 12(3), 383-398. https://doi.org/10.1016/0304-3932(83)90060-0

Casares, M., Moreno, A., \& Vázquez, J. (2014). An estimated New-Keynesian model with unemployment as

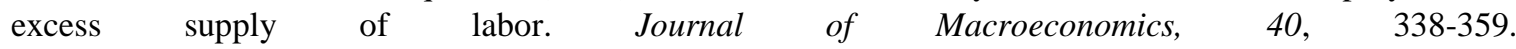
https://doi.org/10.1016/j.jmacro.2014.01.010

Chu, S. Y., \& Shane, C. (2017). Using the hybrid Phillips curve with memory to forecast US inflation. Studies in Nonlinear Dynamics \& Econometrics, 21(4). https://doi.org/10.1515/snde-2016-0088

Clarida, R. H. (1990). International lending and borrowing in a stochastic, stationary equilibrium. International Economic Review, 543-558. https://doi.org/10.2307/2527160

Durevall, D., \& Sjö, B. (2012). The dynamics of inflation in Ethiopia and Kenya African Development Bank Group, Working Paper. Retrieved from http:/www.afdb.org/

Friedman, M. (1995). The role of monetary policy. Essential Readings in Economics, 215-231. https://doi.org/10.1007/978-1-349-24002-9_11

Gal1, J., \& Gertler, M. (1999). Inflation dynamics: A structural econometric analysis. Journal of monetary Economics, 44(2), 195-222. https://doi.org/10.1016/S0304-3932(99)00023-9

Gil-Alana, L. A., \& Mudida, R. (2017). CPI and inflation in Kenya. Structural breaks, non-linearities and dependence. International Economics, 150, 72-79. https://doi.org/10.1016/j.inteco.2016.12.003

Gokal, V., \& Hanif, S. (2004). Relationship between inflation and economic growth. Retrieved from https://pdfs.semanticscholar.org/ec9e/7acbe2d29c1b67b48a865da9ce90e382627f.pdf

Huizinga, F., Geda, A., Ndun'gu, N. S., \& Karingi, S. N. (2001). Theoretical base for the Kenya macro model: The KIPPRA-Treasury macromodel. Retrieved from https://www.acronymattic.com/KIPPRA-Treasury-Macro-Model-(KTMM).html

Kajuth, F. (2012). Identifying the Phillips curve through shifts in volatility. Journal of Macroeconomics, 34(4), 975-991. https://doi.org/10.1016/j.jmacro.2012.08.006

Lucas, R. E. (1973). Some international evidence on output-inflation tradeoffs. The American Economic Review, 63(3), 326-334. https://www.jstor.org/stable/1914364

Misati, R. N., \& Munene, O. (2015). Second Round Effects And Pass-Through Of Food Prices To Inflation In Kenya. International Journal of Food and Agricultural Economics, 3(3), 75. Retrieved from http://www.foodandagriculturejournal.com/vol73.no73.pp75.pdf

Mutuku, C., \& Ng'eny, K. L. (2014). Macroeconomic variables and the kenyan equity market: A time series analysis. Business and Economic Research, 5(1), 1-10. https://doi.org/10.5296/ber.v5i1.6733

Nguyen, A. D. M., Dridi, J., Unsal, F. D., \& Williams, O. H. (2017). On the drivers of inflation in Sub-Saharan Africa. International Economics, 151, 71-84. https://doi.org/10.1016/j.inteco.2017.04.002

Nyongesa, D., Lubega Amlega, E., \& Odhiambo, S. (2017). The Relationship between Inflation and Economic Growth in East African Community Countries. Retrieved from https://www.researchgate.net/publication/322924454_The_Relationship_between_Inflation_and_Economic _Growth_in_East_African_Community_Countries

Phelps, E. S. (1968). Money-wage dynamics and labor-market equilibrium. Journal of Political Economy, 76(4, Part 2), 678-711. https://doi.org/10.1086/259438

Phillips A .W. (1958). The Relation Between Unemployment and the Rate of Change of Money Wage Rates in the United Kingdom, 1861-1957 1. Economica, 25(100), 283-299. https://doi.org/10.2307/2550759

Roseline Nyakerario Misati, E. M. N., Lucas, K. N., \& Sheila, K. (2012). Feasibility of inflation targeting in an 
emerging market: Evidence from Kenya. Journal of Financial Economic Policy, 4(2), 146-159. https://doi.org/10.1108/17576381211228998

Samuelson, P. A., \& Solow, R. M. (1960). Analytical aspects of anti-inflation policy. The American Economic Review, 50(2), 177-194.

Tesfaselassie, M. F., \& Wolters, M. H. (2018). The impact of growth on unemployment in a low vs. a high inflation environment. Review of Economic Dynamics, 28, 34-50. https://doi.org/10.1016/j.red.2017.07.005

Were, M., Nyamongo, E., Kamau, A., Sichei, M., \& Wambua, J. (2014). Assessing the effectiveness of monetary policy in Kenya: Evidence from a macroeconomic model. Economic Modelling, 37, 193-201. https://doi.org/10.1016/j.econmod.2013.11.004

Xu, Q., Niu, X., Jiang, C., \& Huang, X. (2015). The Phillips curve in the US: A nonlinear quantile regression approach. Economic Modelling, 49, 186-197. https://doi.org/10.1016/j.econmod.2015.04.007

Zhang, C., Osborn, D. R., \& Kim, D. H. (2009). Observed inflation forecasts and the New Keynesian Phillips curve. Oxford Bulletin of Economics and Statistics, 71(3), 375-398. https://doi.org/10.1111/j.1468-0084.2009.00544.x

\section{Notes}

Note 1. For instance, agriculture, mining, manufacturing, building and construction, service etc. (ERA, 2016; KER, 2017).

Note 2. Through Kenya Institute of Public Policy Research Analysis, the institute not only trains state economist attached to the Central Planning Unit in macro modelling but also officials from East African countries like Malawi, Uganda Rwanda Ethiopia among others to design sustainable macro-models for their economies. (KER, 2017).

Note 3. The model constituted essential economic sectors tuned to reflect the banks objectives. Refer to Were, M., 2014 for comprehensive model account and the Kenya Economic Report 2017.

\section{Copyrights}

Copyright for this article is retained by the author(s), with first publication rights granted to the journal.

This is an open-access article distributed under the terms and conditions of the Creative Commons Attribution license (http://creativecommons.org/licenses/by/4.0/). 